\title{
APLICABILIDADE DA PROGRAMAÇÃO MATEMÁTICA MULTIOBJETIVO NO PLANEJAMENTO DA EXPANSÃO DE LONGO PRAZO DA GERAÇÃO NO BRASIL
}

\author{
Leonardo Lins de Albuquerque \\ Eletrobrás \\ Rio de Janeiro - RJ \\ leonardo.lins-albuquerque@eletrobras.com \\ Adiel Teixeira de Almeida* \\ Cristiano Alexandre Virgínio Cavalcante \\ Universidade Federal de Pernambuco (UFPE) \\ Recife - PE \\ almeidaatd@gmail.com; cristianogesm@gmail.com \\ * Corresponding author / autor para quem as correspondências devem ser encaminhadas \\ Recebido em 05/2008; aceito em 12/2008 após 1 revisão \\ Received May 2008; accepted December 2008 after one revision
}

\section{Resumo}

O trabalho evidencia a aplicabilidade da Programação Linear Multiobjetivo no planejamento da expansão de longo prazo da geração do sistema elétrico brasileiro. Para melhor viabilizar a utilização da programação linear multiobjetivo no contexto em sistemas fortemente hidrelétricos, como o do Brasil, é explorada uma abordagem gráfica e proposto um procedimento. Por meio deste, permite-se encontrar a composição ótima de um sistema hidrotérmico para atender montantes projetados de energia elétrica no futuro, a qual se beneficie, também, das hidrologias favoráveis e de maior probabilidade de ocorrência, adotando-se, todavia, proteção contra períodos de vazões reduzidas com o uso de usinas térmicas de segurança flexíveis e de forma econômica. Como resultado deste trabalho, conclui-se que a metodologia de programação linear multiobjetivo tem amplo campo de utilização no contexto do novo modelo institucional do setor elétrico brasileiro, no qual o planejamento da expansão, coordenado pelo Governo Federal, será, naturalmente, foco de naturais e até conflitantes pressões e de objetivos a se considerar.

Palavras-chave: planejamento de energia; decisão multicritério.

\begin{abstract}
The paper shows the application of Multiobjective Linear Programming with regard to the long-term planning of expanding the generation of electricity in Brazil. In order to apply linear multiobjective programming better in the context of powerful hydroelectric systems as has been occurring in Brazil, an approach is explored and a procedure considered which will allow the optimal composition of hydro-thermal systems to be found for supplying the electric energy requirements projected, for the future, which will benefit favorable flows and the greater probability of this occurring. However, at the same time there is a need to adopt protective measures against a period of reduced out-flow due to the use of thermo-electricity stations, for security and economic reasons. The results of this paper lead to the conclusion that the methodology of linear multiobjective programming has a wide field of application in the context of the new institutional model for the Brazilian electricity sector, in which the planning of expansion to be projected by the federal government, will, of course, be the focus of natural conflicting pressures from different agents and have multiple objectives to consider.
\end{abstract}

Keywords: energy planning; multicriteria decision. 


\section{Introdução}

Os processos e as decisões de planejamento da expansão dos sistemas de produção de energia elétrica são, indiscutivelmente, de elevado interesse da sociedade de qualquer Nação, porquanto a eletricidade é um insumo estratégico. A Nação necessita ter sempre presente e atualizada a sua estratégia de expansão do abastecimento de eletricidade. Afinal, uma boa resposta do sistema elétrico que esteja em operação depende da dedicação de como foi bem planejado. Gargalos de hoje são, em geral, consequências de ontem.

No passado, planejar a expansão do sistema elétrico era uma responsabilidade direta e indissociável da empresa que tivesse a incumbência de atender os requisitos de energia elétrica da sua região, que podia ser uma cidade, um ou vários estados, ou mesmo todo um país. A empresa tinha um contrato firmado com o poder concedente, ou seja, era uma concessionária de prestação de um serviço de utilidade pública. A indústria de energia elétrica cresceu e se estruturou, assim, no âmbito mundial, segundo o modelo de monopólio de suprimento regional.

O planejamento da expansão dos sistemas de geração, de transmissão e de compras de energia elétrica, desenvolvido pelas concessionárias, era fundamentalmente mono-objetivo, ou seja, tinha como foco minimizar o custo total da expansão formado pelos custos fixos de investimentos e custos variáveis de operação e de aquisição da energia complementar requerida, o que leva a se oferecer a menor tarifa possível aos consumidores.

Contudo, a partir do final dos anos 80's os monopólios elétricos começavam a ser questionados e pela força natural do direito de liberdade ou livre escolha, os grandes consumidores, antes cativos das concessionárias, começaram a buscar quebrar as barreiras elétricas, forçando as concessionárias a permitir trânsito de energia elétrica de terceiros através das linhas de transmissão de propriedade delas. Com isso, um mercado de energia elétrica começou a se desenhar, atraindo investidores privados.

Baseado nessa premissa criou-se o modelo de acesso aberto ou também chamado de modelo de competição na geração de energia elétrica, e, como decorrência, a crescente liberdade na comercialização do produto energia elétrica. A transmissão e a distribuição passaram a ser vistas como serviços. Ou seja, a rede e os fios mantiveram-se regulados, como monopólios naturais.

Em um modelo de competição na sua forma pura, como inicialmente pensando, não haveria mais a necessidade de coordenação, no plano governamental, do planejamento da expansão dos sistemas elétricos de um país, aspecto esse característico de uma economia planejada. Diziam os defensores da competição, no máximo haveria um planejamento apenas indicativo.

No Brasil, contudo, felizmente saímos do modelo de planejamento da expansão confiado apenas ao mercado. A base hidrelétrica elevada e o ainda grande potencial hidrelétrico competitivo a se aproveitar não se coadunam com o modelo de competição na sua forma pura. A competição, no Brasil, na expansão da geração tem que ser controlada e guiada, ainda por algum tempo. Pelo menos até que ainda seja de interesse da Nação o aproveitamento do potencial hidroelétrico remanescente, uma fonte energética renovável.

Tendo a ELETROBRÁS sido retirada, em 1999, da coordenação do planejamento da expansão dos sistemas elétricos brasileiros e essa missão tendo passado para a alçada do Ministério de Minas e Energia, haverá que se buscar uma permanente atualização dos planos de expansão do setor energético e, em particular, do setor elétrico. Não apenas os planos 
decenais de curto prazo, mas também os de longo prazo, de 20 a 30 anos à frente, que propiciam efetiva direção às políticas energéticas para atendimento ao mercado crescente de eletricidade.

Em estudos de planejamento da expansão de longo prazo da geração, um dos aspectos relevantes é o da definição da composição ótima do parque gerador, ou seja, a otimização do "mix energético" de produção de eletricidade.

No Brasil, no entanto, com a maior ênfase à utilização da hidroeletricidade, em geral, têm-se priorizado o uso de modelos de simulação para avaliar alternativas de expansão, ao invés de modelos de otimização que gerem diretamente as composições e programações ótimas do parque gerador. Ressalte-se que o tratamento da hidroeletricidade, em face da estocasticidade da mesma, é um desafio nas metodologias de otimização da expansão de longo prazo da geração.

Por outro lado, com o planejamento da expansão a cargo do Governo e não das empresas, é natural que os objetivos a se otimizar sejam múltiplos, pois, mesmo que se continue dando a necessária ênfase à minimização do custo total da expansão, haverá de se considerar outros objetivos, tais como: aspectos estratégicos da Nação, impactos e custos ambientais, segurança energética, confiabilidade elétrica, geração de empregos, nível de produção da indústria nacional de bens e serviços, inserção regional e desenvolvimento tecnológico.

\section{Descrição do Problema}

O problema do planejamento da expansão da geração, no seu contexto clássico, segundo Albuquerque (2004), consiste em buscar definir a melhor composição da evolução do parque gerador de energia elétrica. $O$ enfoque clássico aplicado em se obter um plano ótimo é buscar a minimização do custo total da expansão, representado pelo valor presente do custo dos investimentos e dos custos de operação e manutenção ao longo do horizonte de planejamento adotado.

A Programação Linear (PL) tem sido uma técnica bastante aplicada nos estudos de planejamento da expansão de longo prazo de sistemas de produção de energia elétrica, adotada a partir dos anos 60's para melhor definição do chamado "mix energético", conforme indicado por Mariz (1985). Formulações matemáticas constam na literatura técnica internacional, principalmente para sistemas com maior participação de termeletricidade, como é indicado em Knight (1972) e Vardi et al. (1981). Em 1980, a ELETROBRÁS também a adotou nos estudos de longo prazo, conforme contido em Trinkenreich et al. (1980), cuja formulação foi adaptada ao sistema brasileiro, devido a sua forte participação hidrelétrica.

Knight (1972) foi um dos estudos pioneiros utilizando a programação linear no planejamento da expansão da geração. Tal trabalho repercutiu em interessantes insights. Nesta abordagem, variáveis como a capacidade da planta (a ser instalada), a energia produzida (a ser injetada no sistema por uma nova planta e em determinada época), a energia produzida anterior a introdução das novas instalações e no ano inicial do horizonte de planejamento eram consideradas. A função objetivo a minimizar é o valor presente sob uma taxa de desconto i, da soma de duas parcelas: (1) o custo de investimento das novas plantas (expressos em \$/MW instalado) e (2) os custos variáveis de produção correspondentes aos montantes de energia elétrica viáveis de produzir pelas usinas. Estas duas parcelas juntas formam o custo do plano de expansão. Tal formulação considera que a curva de demanda de energia elétrica

Pesquisa Operacional, v.29, n.1, p.153-177, Janeiro a Abril de 2009 
é variável, ao longo do dia, da semana e dos meses, o que leva a se ter que construir uma curva de duração da carga anual, a qual pode variar ao longo dos anos a depender de políticas de gerenciamento da demanda ou da natureza e composição da carga dos consumidores.

A curva de duração de carga ou, no inglês, load-duration-curve (LDC), tem um formato semelhante ao apresentado na Figura 1. Ela pode ser aproximada, nos estudos de expansão de longo prazo de geração, por alguns intervalos (patamares de magnitude e duração diferentes), evidenciados, na referida figura, para o caso de três intervalos $(m=1,2,3)$, que formam um subperíodo de 8760 horas (um ano), com a condição de que, no conjunto, correspondam, em área integrada, à energia elétrica total esperada de ser requerida, do sistema produtor, pelo mercado a ser suprido. As LDC's podem ser construídas e usadas, com diferentes durações de subperíodos e de intervalos, como, por exemplo, triênios ou quinquênios.

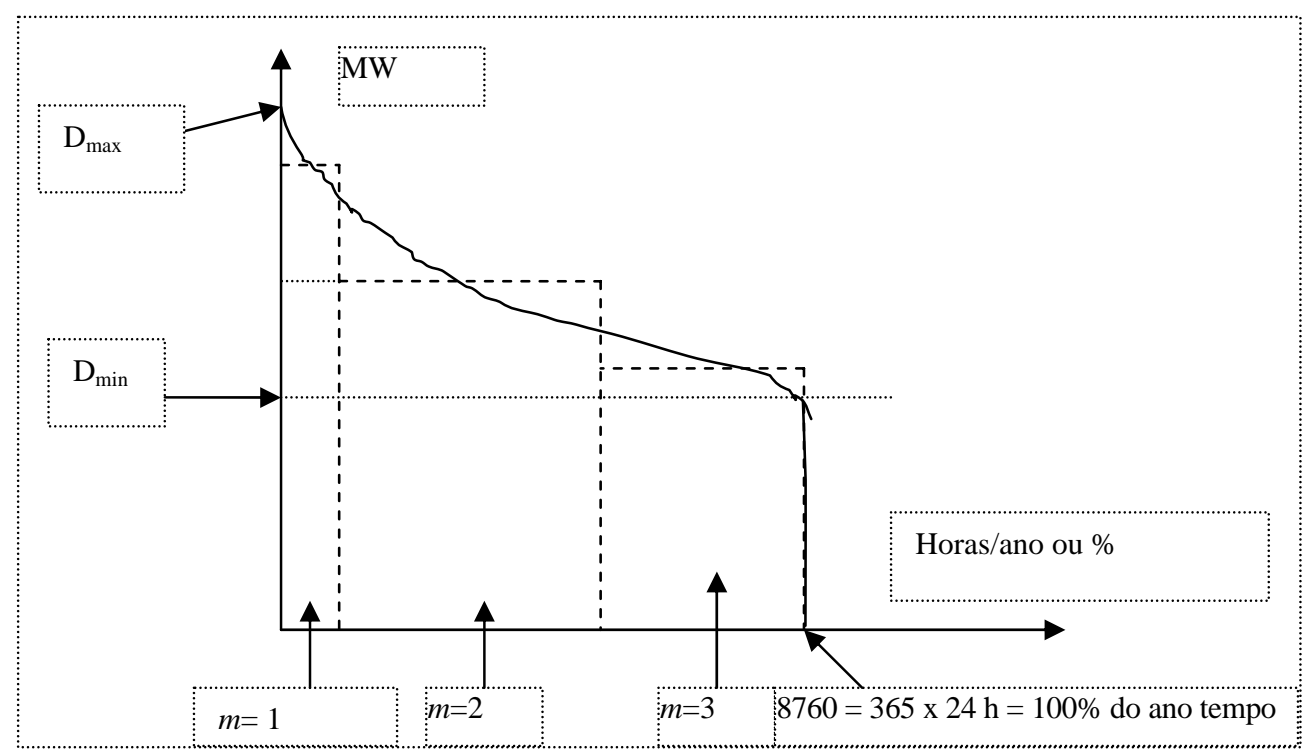

Figura 1 - Curva típica de duração de carga, utilizada com três patamares.

Na abordagem de Verdi \& AVI-Itzhak (1981) a ferramenta básica é também a LDC. O que os autores têm em mente é que os sistemas geradores de energia elétrica, de maior porte, são compostos por usinas de diferentes insumos energéticos, entre elas, unidades térmicas para operação em complementação ou para suprir os picos de demanda e outras para assumirem a carga de base. Tais autores consideram a PL como instrumento de apoio para os estudos de expansão de longo prazo dos sistemas de geração, pois possibilitam obtenção direta de solução ótima, porém, para os estudos de curto prazo eles recomendam modelos de simulação, o que coincide com a visão apresentada por Mariz (1985).

A abordagem de Trinkenreich et al. (1980), desenvolvida para a ELETROBRÁS no final dos anos 70's, foi aplicada em um modelo de otimização da composição da expansão do parque gerador brasileiro, utilizando programação linear. O modelo foi denominado de DESELP,

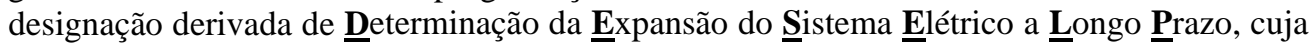


modelagem tem muito do que foi exposto em Knight (1972), assim como em Verdi \& Avi-Itzhak (1981). Tal modelo foi a ferramenta de apoio aos estudos técnicos que suportaram o Plano 2000, o Plano 2010 e o Plano 2015. Os modelos que, na época, existiam disponíveis em outros países não contemplavam sistemas hidrelétricos de grande porte como havia no Brasil.

O modelo DESELP considera, na definição do programa de composição ótima, a produção de energia elétrica das usinas hidrelétricas como sendo igual à energia produzível no período crítico (menor sequência de vazões), o que significa um critério de garantia para a hidrologia, valorizando também a energia secundária que possa ser gerada pela capacidade instalada adicional à capacidade de base a ser instalada na usina.

Por outro lado, o modelo também considera aspectos geográficos tendo em vista que o sistema elétrico brasileiro, em face da grande extensão territorial do país, é formado por subsistemas ou regiões elétricas, no qual cada uma das regiões pode ter tanto carga como geração, seja, hidrelétrica, usina reversível ou termelétrica, de diferentes tipos, sendo os subsistemas interligados por troncos de transmissão. Um pouco diferente de Knight (1972), o DESELP não trata de capacidades de exportação ou de importação de cada área de geração, mas sim de limites de intercâmbios entre regiões, o que permite se representarem a distribuição e o acoplamento eletrogeográfico entre as diversas áreas.

A duração de tempo dos subperíodos do período ou horizonte de planejamento pode ser definida igual a um ano ou grupos sequenciais de anos, do tipo biênio, triênio ou quinquênio. Normalmente, nos estudos de horizonte de planejamento de 20 a 30 anos, da ELETROBRÁs, adotavam-se períodos com duração de 5 anos, para tornar compatível com a duração do período crítico hidrológico ocorrido entre 1952 e 1955, além de diminuir o número de variáveis. A modelagem do mercado é feita por uma curva de duração de carga (LDC), em dois patamares, o que permite analisar também a questão do atendimento à ponta.

Como variáveis de decisão, tem-se a indicação de novas usinas a implantar, em cada período, escolhidas a partir de uma relação de projetos candidatos e associados a subsistemas definidos que os comportassem ou a eles estivessem vinculados (caso típico de projetos hidrelétricos), bem como a possibilidade de indicação de ampliação ou criação de troncos de transmissão.

Cada variável de decisão tem associado custo de investimento, em $\$ / \mathrm{kW}$, e custos de operação, em \$/MWmédios. No caso dos projetos termoelétricos, tem-se o custo do combustível, em \$/MWmédios.

A função-objetivo é minimizar o valor presente do custo total da expansão do sistema como um todo, de forma que a indicação de ampliação da oferta de energia (ou de ponta) em um subsistema poderá vir a ser feita tanto por indicação de ampliação de geração no subsistema, como por indicação de ampliação dos troncos de transmissão, se esta for solução mais econômica.

Ocorre que não apenas a minimização do custo é importante a ser considerada. Cada vez mais, outros objetivos são também necessários serem considerados, tais como questões de minimização de impactos ambientais, assim como a consideração da segurança do próprio atendimento energético, o que tem indicado aplicabilidade das técnicas de Programação Linear Multiobjetivo (PLMO). Uma boa referência consta em Clímaco et al. (2003), tratando a modelagem do planejamento da expansão de sistemas geradores de energia elétrica com em avaliação simultânea de três objetivos distintos, quais sejam: (1) Minimizar o custo total do plano de expansão (semelhantemente ao considerado por Knight (1972), 
por Verdi \& Avi-Itzhak (1981) e por Trinkenreich et al. (1980), em verdade este objetivo corresponde ao valor presente do custo total do plano de expansão); (2) maximizar a confiabilidade do atendimento à demanda e, finalmente, (3) minimizar o impacto ambiental derivado da introdução das novas plantas geradoras.

Como restrições ao problema, Clímaco et al. (2003) utilizam condicionantes semelhantes àqueles indicados por Knight (1972), Verdi \& Avi-Itzhak (1981) e também por Trinkenreich et al. (1980). Trabalhando o problema no espaço dos pesos alocados aos objetivos, várias regiões de soluções não dominadas são identificadas, dando-se ao decisor informações diretas sobre os valores respectivos das três funções objetivo. Identificadas as regiões de indiferenças, torna-se possível a escolha da solução de compromisso que melhor satisfaça ao decisor. O que se destaca da metodologia desenvolvida por Clímaco et al. (2003), é a possibilidade de se permitir o processo interativo através do diálogo decisor-analista-modelo.

Quanto à aplicabilidade da modelagem PLMO no planejamento da expansão da geração no Brasil o desafio ainda em aberto é tratar, na modelagem, a variabilidade da geração hidrelétrica, aspecto que abordaremos, de início, no item seguinte.

No caso Brasil, com o Governo Federal estando responsável pela condução do planejamento da expansão da geração para atendimento ao mercado a curto, médio e longo prazo, continua aplicável às mesmas formulações anteriores, do modelo de monopólio regulado, no qual o agente "monopolista", no caso, é o Governo Federal. Dessa forma, conclui-se que se dedicar a adaptar a formulação PLMO, apresentada em Clímaco et al. (2003), à situação característica de sistemas com alta preponderância de hidroeletricidade aleatória, como existente no Brasil, é atrativo.

\section{Modelo Proposto}

Ao se formular um plano de atendimento a um dado volume de carga (demanda de energia elétrica) no futuro, a questão que se coloca é qual a melhor composição do parque gerador, ou seja, qual deve ser o "mix energético" das plantas (usinas) geradoras a se utilizar. Como o que se deseja é energia elétrica, a questão básica no planejamento da expansão da geração a longo prazo é a de quanto se usar de hidrelétricas e quanto de termelétricas, dos diferentes tipos de combustíveis (derivados de petróleo, gás natural, carvão, nuclear ou biomassa), ou mesmo, quanto de outras fontes alternativas (energia eólica, energia solar, célula combustível) e quanto de programas de gerenciamento pelo lado da demanda (demand-sidemanagement - DSM). Um plano de expansão será ótimo se ele otimizar um objetivo que seja definido, ou se satisfizer, de uma forma aceitável, um conjunto de múltiplos objetivos.

Refletindo sobre o contexto do Brasil e considerando que não mais se está sob o modelo de monopólio de suprimento regional, no qual a otimização mono-objetivo era a adotada, os seguintes objetivos seriam passíveis de consideração nos estudos de expansão a longo prazo da geração de energia elétrica no Brasil:

\section{Objetivo 1: minimização do custo total do plano de expansão}

Esse será sempre um objetivo básico. Expansão da geração elétrica para um país significa a mobilização de elevado montante de recursos financeiros. O quanto for possível se reduzir, tal montante será sempre melhor, tanto para o consumidor de energia elétrica, que irá de fato pagar a expansão, como para viabilizar a realização do próprio plano de expansão. 


\section{> Objetivo 2: minimização dos impactos ambientais}

Indiscutivelmente, a questão ambiental é um assunto amplamente debatido no contexto atual visto que cresce o nível de consciência dos indivíduos sobre as limitações do planeta em que habitamos. A sustentabilidade ambiental é um pressuposto que será sempre levado em conta, e crescentemente, no planejamento da expansão da geração em qualquer Nação.

\section{> Objetivo 3: maximização da confiabilidade energética}

Diferentemente do que se apresenta em Clímaco et al. (2003), em um sistema elétrico da dimensão do brasileiro, mesmo no plano regional de um dos seus subsistemas, a confiabilidade elétrica, se entendida apenas como a questão de minimizar a LOLP (loss of load probability), isto é, o risco de perda de carga por desligamento de usinas geradoras individuais, não é uma questão tão crítica e menos será com a continuidade que haverá na ampliação das interligações inter-regionais. Contudo, confiabilidade energética, que pode ser mais bem chamada de segurança energética, significando se dispor efetivamente, no futuro, da energia idealizada de ser produzida por determinado tipo de planta geradora, é uma questão que o planejamento da expansão sempre enfrenta.

Pelo lado das hidrelétricas, para as quais não existe um balcão para se comprar o combustível, o que normalmente se usa é definir um nível de garantia que seja julgado aceitável, com base em estudo estatístico das séries de vazões naturais dos rios nos quais se localizam, ou se localizarão, as usinas. No Brasil, o nível de garantia adotado para a hidroeletricidade tem sido de $95 \%$, desde meados dos anos 80 , que equivale a usar um risco de não garantir de $5 \%$.

Por parte das termelétricas, o que, normalmente, se faz é definir uma reserva de MW_ano. Isto é feito adotando-se um redutor na capacidade máxima de produção dessas usinas, denominado de fator de capacidade ou fator de disponibilidade, que leva em conta indisponibilidades das unidades para manutenção ou saídas forçadas. Diferentemente das hidrelétricas, tem-se um balcão onde comprar o combustível. Assim, a disponibilidade do combustível é, em tese, resolvida em um contrato, que defina preço e condições de disponibilização. Ao se usar termelétricas, de qualquer tipo de combustível, seja fóssil, nuclear ou biomassa, no planejamento do atendimento elétrico futuro de um país, é muito importante o estudo de sensibilidade com relação aos preços desses combustíveis, no longo prazo.

Claro que, em problemas de otimização multiobjetivo, podem ser usadas restrições no lugar de um objetivo. Entretanto, com um objetivo explícito associado à confiabilidade energética, com o uso de PLMO, pelo método contido em Clímaco et al. (2003), o decisor teria uma melhor sensibilidade sobre o impacto da confiabilidade energética nos outros objetivos, permitindo-se posicionar, dessa maneira, com flexibilidade, onde a efetiva segurança energética deva se situar.

\section{$>$ Outros objetivos}

Na condução ao nível do Governo Federal do planejamento da expansão de longo prazo da geração de energia elétrica para o Brasil, não haverá como não se inserir outros objetivos, além dos três anteriores comentados. Alguns serão, inclusive, não traduzíveis em equações matemáticas. Serão políticas ou políticos.

O desenvolvimento tecnológico é um deles. Decorre de política energética com visão de longo prazo. Sinalizar que determinada opção energética constará da matriz de produção de 
eletricidade no futuro, significará atrair pesquisas e investidores na dita opção. Neste campo, inserem-se as denominadas fontes alternativas (eólica, solar e células combustíveis).

Mobilizar capitais privados para criar empregos no campo é político. Interessará, sempre, a qualquer Administração eleita e instalada no Governo Federal do Brasil, demonstrar a população que está firmemente comprometido em reduzir o êxodo rural que tanto males tem e está causando às grandes cidades, aumentando, a cada dia, os níveis de violência urbana. Neste contexto, como alternativa energética, pode se situar a geração elétrica com base na biomassa que gera centenas de emprego por unidade de MW_ano produzível.

A consideração desses objetivos adicionais no planejamento da expansão a longo prazo da geração de energia elétrica no Brasil pode ser, facilmente, contemplada na formulação matemática de otimização do "mix energético", seja criando funções lineares dos percentuais de participação de cada tipo de planta (usina) a instalar, ponderados por pesos ou mesmo utilidades relativas, quer definindo-se limites mínimos admissíveis, por razões de política energética, nas participações das fontes estratégicas.

Em síntese, a abordagem de Programação Linear Multiobjetivo tem forte vocação, na visão dos autores deste trabalho, para ser introduzida nos estudos de planejamento da expansão de longo prazo da geração de energia elétrica no Brasil, a serem desenvolvidos pela Empresa de Pesquisa Energética (EPE), sob a orientação do Ministério de Minas e Energia (MME), sendo este o responsável por conduzir e levar ao Conselho Nacional de Políticas Energéticas (CNPE) as sugestões de medidas para garantir o equilíbrio da oferta e demanda de energia elétrica, a curto, médio e longo prazo. Em síntese, no Brasil de hoje, o monopólio do planejamento é do Governo Federal!

É nesse contexto de monopólio de planejamento, colocado no âmbito do Estado, chamada por alguns como competição tropicalizada, que a otimização multiobjetivo, na visão dos autores deste trabalho, apresenta-se como plenamente aplicável.

Tendo como referência o que foi acima exposto, apresenta-se possível, na visão dos autores, que o planejamento da expansão da geração de energia elétrica no Brasil, sob a condução do MME, possa ser desenvolvido segundo uma metodologia que contemple dois tipos de problemas:

a) definição da trajetória da composição ótima do “mix energético" do parque gerador de energia elétrica com um horizonte de longo prazo (20 a 30 anos à frente) e das indicações de ampliações de, ou novas, interligações inter-regionais e com países vizinhos;

b) determinação da indicação da programação ótima para um horizonte de 10 (dez) anos de entradas em operação de usinas dos diferentes tipos e das ampliações requeridas nos sistemas interligados de transmissão, tendo como referência a trajetória da composição ótima do "mix energético" de longo prazo.

No desenvolvimento da solução do primeiro problema, com base em modelo de otimização, poder-se-ia utilizar a PLMO, com a metodologia de abordagem contida em Clímaco et al. (2003) e utilizando-se do algoritmo apresentado em Albuquerque (2004), para se definir a trajetória da composição ótima do "mix energético" do parque gerador de energia elétrica em três ou quatro janelas dentro do horizonte de longo prazo.

Em cada janela, definir-se-ia a composição ótima do "mix energético", para diferentes cenários de mercado que se utilizasse. Essas janelas poderiam ser anos, ou períodos de 
duração maior, tipo triênios ou mesmo quinquênios, que se justaporiam. Pelas composições ótimas escolhidas pelo decisor, apoiado em PLMO, ter-se-ia a trajetória da composição ótima do "mix energético" para o horizonte de planejamento de longo prazo definido.

Com base nessa visão de longo prazo da expansão da geração e do estudo da localização dos potenciais hidrelétricos competitivos que fossem contemplados dentro do volume de geração hidrelétrica integrante da trajetória da composição ótima do "mix energético", seriam identificadas as ampliações requeridas nas interligações inter-regionais do Brasil, assim como, nas novas interligações, inclusive com países vizinhos, e também estimativas de custos de expansões na rede básica nacional, junto aos centros de carga, para absorver os incrementos de fluxos de potências.

Opcionalmente, essas análises exploratórias da expansão do sistema de transmissão nacional permitiriam indicação de ajustes nos custos de investimentos e nas gerações que, efetivamente, se disporiam das hidrelétricas referidas aos centros de carga, o que poderiam servir em refinamentos e ajustes nas próprias composições ótimas.

Ressalte-se que o Plano Estratégico Nacional de Longo Prazo da Expansão da Geração de Energia Elétrica, atualizado a cada quatro anos, ou seja, dentro de cada período de gestão da Administração Federal eleita, seria uma das entradas para a formulação da trajetória de longo prazo da Matriz Energética Nacional, assim como receberia entrada dela.

No que concerne ao segundo problema, que é a determinação da programação ótima de usinas, interligações inter-regionais e ampliações no sistema de transmissão nacional, para um horizonte de 10 (dez) anos, isto se constituiria no desenvolvimento e na emissão, em cada ano, do Plano Decenal de Expansão, adotando-se exatamente o que era feito, e bem, pelo Grupo Coordenador do Planejamento do Sistema Elétrico (GCPS).

Com o suporte de modelos de simulação seriam identificados no Plano Decenal de Expansão quantos MW's deveriam ser agregados anualmente ao Sistema, e onde, tendo como alvo a trajetória da composição ótima do "mix energético" definido no Plano Estratégico de Longo Prazo, retro comentado.

\section{Discussão e aplicação do Modelo Proposto}

Há, ainda no Brasil, uma visão de que a formulação do planejamento da expansão da geração de energia elétrica do sistema brasileiro não se coaduna muito bem com aplicação de técnicas de otimização, tais como as técnicas apresentadas em (Clímaco et al., 2003 e Knight, 1972). Essa colocação se baseia na grande dimensão da nossa base hidrelétrica e na elevada aleatoriedade das afluências médias anuais.

Contudo, Guedes Filho et al. (2003) apresentaram uma interessante abordagem para superar a questão da variabilidade da geração hidrelétrica no problema de otimização do " $m i x$ energético". O foco da abordagem foi o de definir qual seria uma composição ótima de geração hidrelétrica e termelétrica para atender a um dado volume de energia total em um período anual no futuro. O estudo foi um marco importante no processo de provocação de desenvolvimento de novas metodologias para planejamento da expansão da geração de energia elétrica no Brasil. Resumidamente, a metodologia que Guedes Filho et al. (2003) desenvolveram consistiu em: 
a) primeiramente definiu-se um valor mais atualizado para o custo social do déficit, expresso em R\$/MWh, que resultou em 2.670,00 R\$/MWh, base 2002, que ao câmbio, da época, de 3,00 R\$/US\$, seria igual a 890,00 US\$/MWh; recordando a abordagem indicada por Verdi \& Avi-Itzhak (1981), este seria o custo de operação da térmica fictícia que representaria a parcela de mercado que viesse a não ser atendido na hipótese de hidrologias muito reduzidas;

b) em seguida, sintetizaram o parque gerador do Sistema Interligado Brasileiro como constituído de uma única usina hidrelétrica, representado por uma usina-reservatório equivalente, e de três tipos de termelétricas (uma de ciclo combinado e duas de ciclo aberto), todas com seus respectivos custos fixos, em US\$ $/ \mathrm{kW}$ incremental a ser instalado, e custos variáveis, em US\$/MWh. No caso das termelétricas, foram adotados diferentes níveis de take or pay (tipo de contrato firme de compra de volumes de gás, em percentagem do volume máximo mensal, para pagamento mesmo sem o uso do gás), quais foram:

Tabela 1 - Dados do sistema hidrotérmico estudado.

\begin{tabular}{|c|c|c|c|}
\hline Tipo & $\begin{array}{c}\text { Custos de } \\
\text { Investimento } \\
\text { (US\$/kW) }\end{array}$ & $\begin{array}{c}\text { Custos variáveis } \\
\text { operacionais } \\
\text { (US\$/MWh) }\end{array}$ & Take or pay \\
\hline Hidro & 950 & 2,06 & - \\
\hline Gás c. combinado & 750 & 16,52 & $70 \%$ \\
\hline Gás c. simples 1 & 450 & 30,14 & $40 \%$ \\
\hline Gás c. simples 2 & 450 & 57,34 & $20 \%$ \\
\hline
\end{tabular}

Veja-se que a térmica fictícia, para representar algum déficit de energia, não tem custo de investimento ou fixo, mas apenas custo variável que é o custo social do déficit, adotado em 890,00 US\$/MWh, portanto, no caso, cerca de 15,5 vezes o custo variável da térmica mais cara (Gás c.simples 2 - take or pay de $20 \%$ ).

c) depois, calcularam uma função de distribuição de probabilidade acumulada para a Geração Hidroelétrica (GH), constituída pela composição da função de distribuição da energia natural afluente ao reservatório equivalente com a função de distribuição de probabilidade do estado estacionário do nível do reservatório no início de um ano qualquer, no futuro distante;

d) em sequência, foi definida a Função de Distribuição Acumulada (FDA) da demanda a ser requerida do parque termelétrico, considerando a formulação que já comentamos no item anterior de GT = ET - GH, onde ET, no caso, foi a demanda total de energia solicitada ao sistema hidrotérmico conjunto, em um dado ano no futuro, considerada como um montante global em TWh, ou seja, como que uma LDC de um único intervalo e com patamar de MW constante (o valor do MWmédio, do período);

e) finalmente, a função contínua de distribuição de probabilidade da Geração Térmica (GT) foi tratada como uma LDC (que pode ser "patamarizada"), sendo usada em um processo de otimização da composição ótima do "mix energético" do parque de geração a ser instalado, cuja função-objetivo foi maximizar a remuneração do parque gerador a ser instalado, o que é um espelho do objetivo de minimizar o custo total expansão. 
A formulação matemática apresentada em Guedes Filho et al. (2003) é relativamente longa para ser transcrita neste trabalho. Contudo, é possível melhor entender com uma "explicação gráfica” que desenvolveremos, no item seguinte, ao apresentar algumas considerações sobre a característica probabilística da geração hidrelétrica $G H$.

\subsection{A característica probabilística da geração hidrelétrica}

O desafio da hidroeletricidade reside, assim, no fato de que a energia média anual natural afluente de um sistema hidrelétrico, exemplificado aqui o Sistema Nordeste, é uma variável aleatória, para a qual, podemos, com base em dados históricos e análises estatísticas e matemáticas, modelar a sua função de distribuição de probabilidade, a qual, na configuração de usinas hidrelétricas de hoje, naquele sistema, é sintetizada na Figura 2.

Pela Figura 2, pode-se, com facilidade, identificar qual o valor da Energia Natural Afluente do Nordeste (ENA_NE) associado a um dado nível de risco $(\alpha)$ de ocorrência de valores iguais ou inferiores a ele, observando que esta curva é função apenas da aleatoriedade das vazões naturais e da produtividade média da configuração do sistema de usinas hidroelétricas, significando, portanto, ser o recurso hidroenergético estruturalmente probabilístico, representativo do abastecimento hídrico oferecido pela Natureza ao sistema de geração hidrelétrica da região, no caso, a do Nordeste do Brasil.

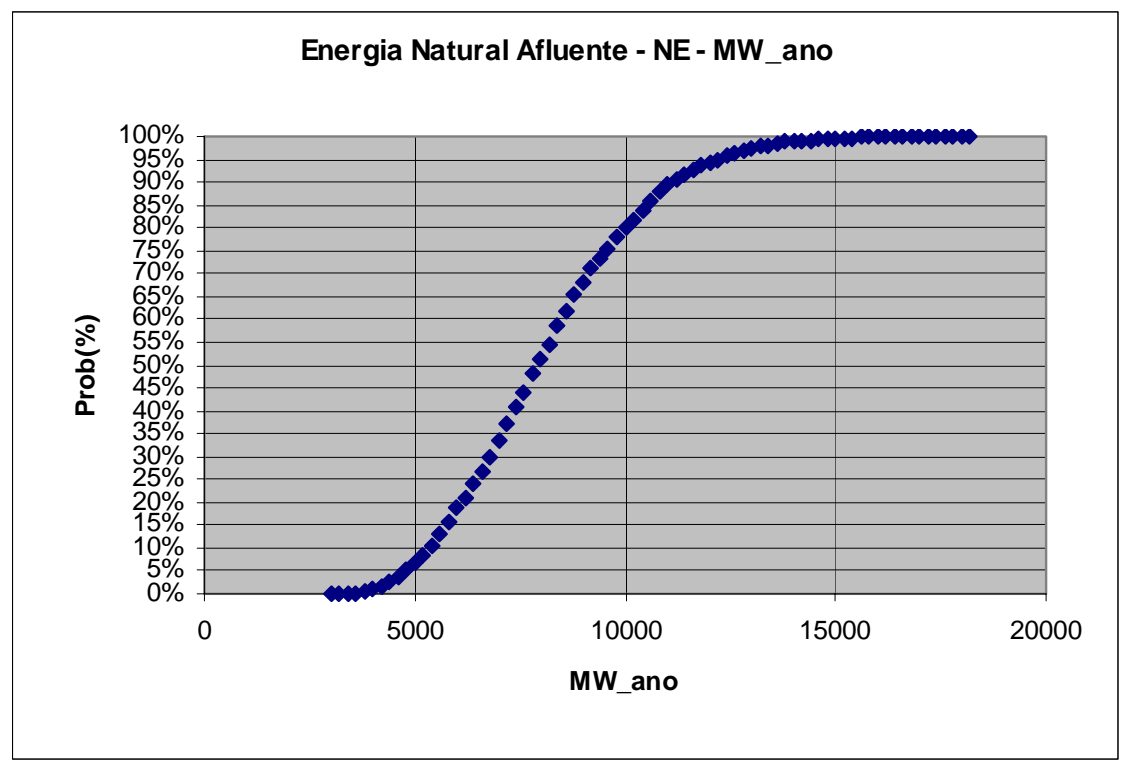

Figura 2 - Probabilidade acumulada de ENA_NE (Sistema Nordeste).

Considerando que a carga média anual total do Sistema Nordeste (Piauí à Bahia) está na ordem de 6300 MW_ano, a Figura 2 indica que são necessárias afluências médias anuais no entorno da correspondente ao nível de risco $\alpha=20 \%$, para que o sistema hidrelétrico do Nordeste possa atender a carga sem o uso de estoques nos reservatórios e/ou de complementação outras. 
Veja-se que, para um $\alpha=5 \%$, representação do nível de risco atualmente adotado como aceitável, tem-se um valor da energia hidrelétrica natural afluente do Sistema Nordeste no entorno de $4.800 \mathrm{MW}$ ano sob uma garantia de $95 \%=(1-\alpha)$, ou seja, um $\operatorname{Var}_{5 \%}$, isto é, valor ao risco de 5\%, da $E N A \_N E$, na configuração de geração atual, é, em números redondos, aproximadamente igual a 4.800 MW_ano.

Um aspecto interessante da curva da FDA, exposta na Figura 1, é que, caso sejam introduzidas, no futuro, novas usinas na focalizada cascata, as quais poderiam ser as usinas de Riacho Seco e Pedra Branca, entre Sobradinho e Itaparica, e a de Pão de Açúcar, à jusante de Xingó, todas em estudos pela CHESF, resultará em uma mudança de escala do eixo da ENA, devido ao incremento que haveria na produtividade média da cascata.

Veja-se que se os reservatórios existentes estiverem plenamente cheios, os respectivos volumes úteis poderiam ser descarregados pelas turbinas para geração de energia elétrica na própria usina associada ao reservatório e naquelas à jusante. Se tal descarregamento fosse feito em um ano, ou seja, em 31,536 x $10^{6}$ segundos, resultaria em uma vazão média anual da ordem de $1.510 \mathrm{~m}^{3} / \mathrm{s}$, para o volume útil total da cascata, de $47.604 \mathrm{hm}^{3}$. Essa vazão média anual multiplicada pelos coeficientes de produtividade das usinas por onde ela efetivamente passasse, transformando-se em energia elétrica, poderia resultar em um montante de cerca 4.088 MW_ano, que se adicionaria à energia natural afluente do período no atendimento à carga, alimentada pelo sistema hidrelétrico. Portanto, iniciando-se um ano com os reservatórios plenamente cheios, o sistema hidroelétrico atual do Nordeste teria condições de atender quase 9.000 MW_ano, e com uma garantia de 95\%. Todavia, no ano seguinte, com os reservatórios vazios, somente poderia atender cerca de 4.800 MW_ano, ao mesmo nível de garantia.

Considerando a ocorrência, no passado, de vários períodos de anos consecutivos com vazões baixas no Rio São Francisco, sendo o mais longo deles o que é chamado, normalmente, de o período crítico, aquele ocorrido de junho de 1952 a novembro de 1955, ou seja, com duração de 42 meses, não seria recomendável tal operação de pleno esvaziamento dos reservatórios em um ano, sem que houvesse segurança em reenchê-lo no ano seguinte. Então, se o volume útil de $47.604 \mathrm{hm}^{3}$ fosse programado para ser usado, não em um ano, mas em 42 meses, isto corresponderia a uma energia de estoque média da ordem de 1.168 MW_ano. Com tal política operativa para os reservatórios, o Sistema Nordeste, teria possibilidade de atender cerca de 6.000 MW_ano, sob um nível de garantia de 95\%, ou seja, ao risco de 5\%.

Cumpre registrar que o montante de energia hidrelétrica garantida, com risco de $5 \%$, do Sistema Nordeste, calculado por simulações considerando tanto as demais usinas hidrelétricas do subsistema Nordeste (Boa Esperança, Itapebi e Pedra do Cavalo), como a operação integrada e interligada com os demais subsistemas do país, é de 6.267 MW_ano, valor este, portanto, menos de $5 \%$ superior ao valor de 6.000 MW_ano, calculado graficamente, o que é um boa e expedita aproximação.

Dessa forma, cabe ficar entendido que se somar capacidade máxima de estoque de energia armazenada $\left(\mathrm{EAR}_{\max }\right)$ de um subsistema, à energia hidrelétrica natural afluente (ENA_NE) ao mesmo, obter-se-á, com razoável aproximação, a capacidade máxima total de atendimento energético da geração hidrelétrica dele, ou seja:

$$
G H=E N A+\mathrm{EAR}_{\max } .
$$

Sendo a ENA uma variável aleatória, $G H$ também o será, já $\mathrm{EAR}_{\max }$ será considerada, aqui, como uma constante. Na realidade, o mais correto, caso se esteja desejando avaliar um horizonte de planejamento a se iniciar no futuro, ao invés de se usar um único valor, o 
$\mathrm{EAR}_{\max }$, é considerar uma distribuição de valores, ou seja, tratar EAR como uma variável aleatória, pois o nível dos reservatórios no início de um ano qualquer (ou outro período) a se analisar, será função da conjuntura do que venha a ocorrer, de hoje até lá, em termos de carga, vazões, usinas disponíveis e gerações utilizadas.

Destarte, retornando ao contido em Guedes Filho et al. (2003), o que eles fizeram, considerando um sistema hidrelétrico equivalente ao Sistema Interligado Brasileiro, foi, por simulação, obter a função de distribuição acumulada da probabilidade de EAR, em um estado estacionário futuro, ou seja, a FDA de $E A R$, e por uma espécie de convolução com a FDA da $E N A$, obtiveram uma FDA para $G H=E N A+E A R$.

Outra forma, aproximada, poderia ter sido usar o valor médio esperado de $E A R$, que, no fundo, representaria uma espécie de fator redutor aplicado sobre o valor de $E A R_{\max }$, o que, na nossa visão, seria suficiente para efeito de aplicação em estudos de planejamento de expansão de geração de_longo prazo, nos quais o que se deseja não são números precisos, mas uma indicação ótima do "mix energético".

Claro que essa consideração sobre o fator redutor aplicada ao valor de $\mathrm{EAR}_{\max }$ é apenas uma possibilidade, para uso em estudos de planejamento de expansão de longo prazo, que reduziria, no caso do subsistema Nordeste, em 467 MW_ano a disponibilidade de $G H$ (7,7\% de redução ao risco de 5\%). Todavia, em nada altera, conceitualmente, o que estaremos a apresentar no item seguinte.

Veja-se, na Figura 2, que, partindo-se de 4.800 MW_ano, aproximadamente o valor da $E N A \_N E$ ao $\operatorname{Var}_{5 \%}$, ou seja, ao nível de risco de $\alpha=5 \%$, a atual capacidade máxima total de atendimento energético da geração hidrelétrica do Sistema Nordeste, também ao mesmo nível de risco, e com um fator redutor de 0,6 sobre o EARmax, é da ordem de 5.500 MW_ano, valor este bem abaixo da carga total atual da região Nordeste, atualmente no entorno de 6.300 MW_ano, realidade esta que demonstra a necessidade da contínua política de gestão hidroenergética integrada dos diversos reservatórios do Sistema Integrado Brasileiro, missão confiada ao ONS, buscando sempre transferir excedentes de energia de uma região superavitária para outra, que esteja com um nível relativo de reserva energética mais inferior.

Isto também evidencia que o sistema Nordeste está se aproximando de uma situação exigindo ampliação do controle da segurança energética, que poderia ser obtida ampliando-se a capacidade de importação de outras regiões ou com um parque termelétrico 100\% flexível, entre 500 a 1.100 MW de capacidade instalada.

Observe-se que a estratégia de aumentar a energia garantida (ao risco de 5\%) total de um sistema hidrelétrico pela via da implantação de novos reservatórios equivale a "deslocar" horizontalmente a curva da FDA da ENA do mesmo, pois significa que uma parte da carga será suprida, não pela ENA, mas pela energia armazenada (EAR), cujo valor de EAR é, conforme já comentamos, dependente da conjuntura das vazões, cargas e configurações que possam ocorrer de hoje até o início do período de avaliação ou planejamento. Tudo se passa, como se o sistema hidrelétrico tivesse duas fontes em paralelo: as vazões afluentes do futuro e o uso do estoque que se tenha armazenado e que se programe usar segundo uma determinada política operativa.

Infelizmente, não mais existem sítios onde possam ser implantados grandes reservatórios no Brasil, seja por razões físicas ou por questões de impacto ambiental, com a mesma facilidade e apoios como foram possíveis no passado, o que torna a participação percentual da EAR e assim do seu efeito, progressivamente, cada vez mais reduzida, no balanço total de atendimento às cargas do Sistema Interligado Brasileiro. 
Em síntese, o que se demonstrou graficamente, neste capítulo, é que ampliar a base hidrelétrica de um sistema de geração pode ser interpretado como alterar a curva da função de probabilidade acumulada da ENA, por dilatação do eixo da variável, ou com algum deslocamento se houver aumento da capacidade de armazenamento do sistema.

\subsection{Exemplificação gráfica da otimização do “mix energético" de um sistema hidrotérmico}

Para melhor entender, o processo de definição da composição ótima do "mix energético" de um sistema hidrotérmico, considerando a abordagem de Guedes Filho et al. (2003), imagine-se um sistema hidrelétrico que tivesse a FDA de GH igual àquela do subsistema Nordeste e atendendo a uma carga da ordem de 6.000 MW_ano, que é representado na Figura 3, abaixo.

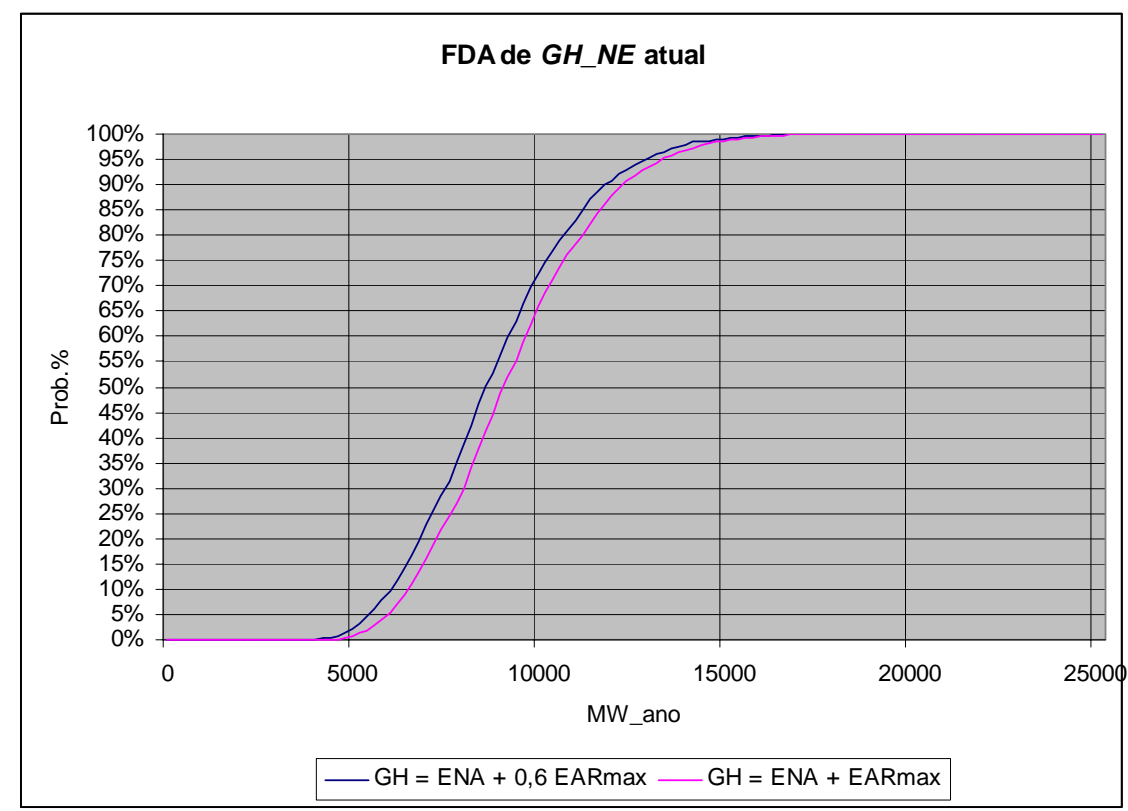

Figura 3 - FDA's de GH_NE, atual, com e sem fator redutor aplicado ao EARmax.

Admita-se, agora, que desejamos definir um plano de expansão de longo prazo da geração para atender a uma carga de 15.000 MW_ano, em um horizonte futuro (20 a 30 anos à frente), o que significaria uma taxa de crescimento da carga entre 3,1 a 4,7\% a.a., implicando em uma necessidade de o sistema vir a receber um reforço de 9.000 MW_ano.

Supondo que houvesse disponibilidade de construir novas usinas e reservatórios nas mesmas cascatas de usinas do focalizado sistema, a um determinado custo marginal da expansão hidrelétrica $\left(\mathrm{CME}_{G H}\right)$, uma solução para o atendimento à carga, conforme já explicamos, poderia ser obtida com o deslocamento e/ou dilatamento da curva da FDA de GH para a direita, de modo que se alcançasse um nível risco também de 5\% para atender aos 15.000 MW_ano, conforme a curva indicada, mais deitada, na qual se admitiu um crescimento de apenas $25 \%$ na $E A R_{\max }$ atual de $47.604 \mathrm{hm}^{3}$. 
O excedente de energia hidrelétrica, embora mantivesse a proporcionalidade, seria demasiado em volume, pelo efeito do extenso dilatamento, da curva da FDA, provocado pelas usinas a fio d'água que reduzem a taxa de declividade ascendente da FDA de GH. Essa seria a alternativa de expansão “100\% hidroelétrica” (ver Figura 4).

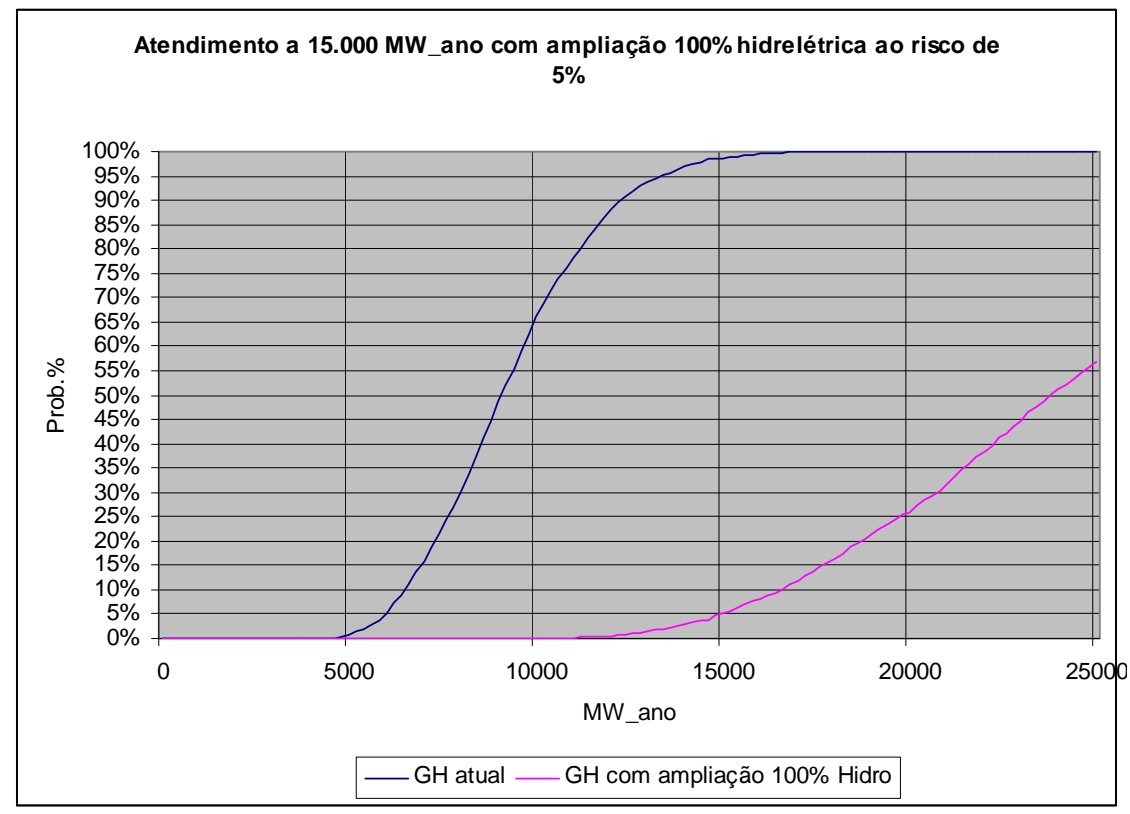

Figura 4 - Planejamento de expansão da geração com ampliação 100\% Hidrelétrica.

O planejamento da expansão da geração, assim sendo feito, poderia ser considerado ótimo, no sentido do mínimo custo e segundo a metodologia que era adotada no passado, na época do modelo de monopólio de suprimento regional, se o $\mathrm{CME}_{G H}$ fosse inferior ao custo unitário de produção de uma geração térmica equivalente para produzir os 9.000 MW_ano adicionais requeridos.

Outro caminho alternativo, com base na abordagem de Guedes Filho et al. (2003), seria implantar um parque térmico que tivesse a capacidade instalada para produzir os 9.000 MW_ano, todavia com flexibilidade, ou seja, as térmicas gerariam apenas em regime de complementação à geração hidrelétrica. Nessa alternativa, o sistema continuaria correndo o risco de 5\% de haver déficit, que é associado aos 6.000 MW_ano originais de geração hidrelétrica. Essa seria a alternativa de expansão “100\% termelétrica”.

Como a mediana da geração hidrelétrica, $G H$ atual, está no entorno de 9.000 MW_ano, havendo capacidade hidrelétrica, para tal, significa que o parque térmico complementar, precisaria gerar, em média, não os 9.000 MW_ano adicionais, porém, um valor esperado no entorno de 6.000 MW_ano, para completar os 15.000 MW_ano.

Haveria, portanto, uma redução esperada da ordem de 33 \% nos 9.000 MW_ano de produção térmica adicional imaginada, fazendo com que a comparação entre os custos da opção de ampliação " $100 \%$ hidrelétrica" e da opção " $100 \%$ termelétrica", devesse ser feita com tal ajuste de fator de uso da geração termelétrica, significando que a solução sob a premissa de expansão 
apenas hidrelétricas só seria a de mínimo custo se houvesse uma margem entre os custos unitários totais de produção (ou índice de mérito) das duas alternativas de expansão, acima consideradas, que compensasse tal redução na efetiva geração esperada de geração térmica.

Claro está que, se fosse instalado apenas 6.000 MW de capacidade de geração térmica, o sistema estaria correndo um risco de $50 \%$ de ter algum déficit, o que seria elevado. Mas com a capacidade de produção térmica em 9.000 MW, o risco de déficit seria os originais $5 \%$ do dimensionamento da energia hidrelétrica "garantida", pois ao se dispor de apenas 6.000 MW_ano hidrelétricos, o parque térmico garantiria os 9.000 MW_ano restantes.

Todavia, se viesse a ser implantada um pouco mais de capacidade de potência térmica, algo como 10.000 MW instalados de térmicas 100\% flexíveis, o risco de déficit seria praticamente nulo e o montante esperado de energia elétrica a ser gerada por esse adicional de segurança seria muito reduzido, fazendo com que tais térmicas de segurança viessem a onerar o custo esperado da expansão apenas pelo custo de capacidade e não pelo de energia a ser produzida.

Caso essa estratégia de expansão " $100 \%$ térmica” apresentasse um custo total superior ao da alternativa de expansão " $100 \%$ hidrelétrica”, o que é esperado, poder-se-ia buscar uma alternativa intermediária, aumentando-se a expansão da base hidrelétrica, que significa deslocar e/ou dilatar a curva da FDA de $G H$ para a direita, provocando redução na capacidade térmica complementar requerida para atender a um mesmo valor de carga total projetada.

Assim, por exemplo, conforme ilustrado na figura a seguir, caso fosse aumentada a base de GH para garantir, com um nível de risco de 5\%, um montante da ordem de 10.000 MW_ano, isto é, dois terços dos 15.000 MW_ano, totais, projetados como requeridos no futuro, o que implicaria em se agregar ao sistema um adicional de apenas 4.000 MW_ano de $G H$ no nível de risco de 5\%, ter-se-ia uma nova curva da FDA de $G H$, não tão dilatada como a anterior (ver Figura 5).

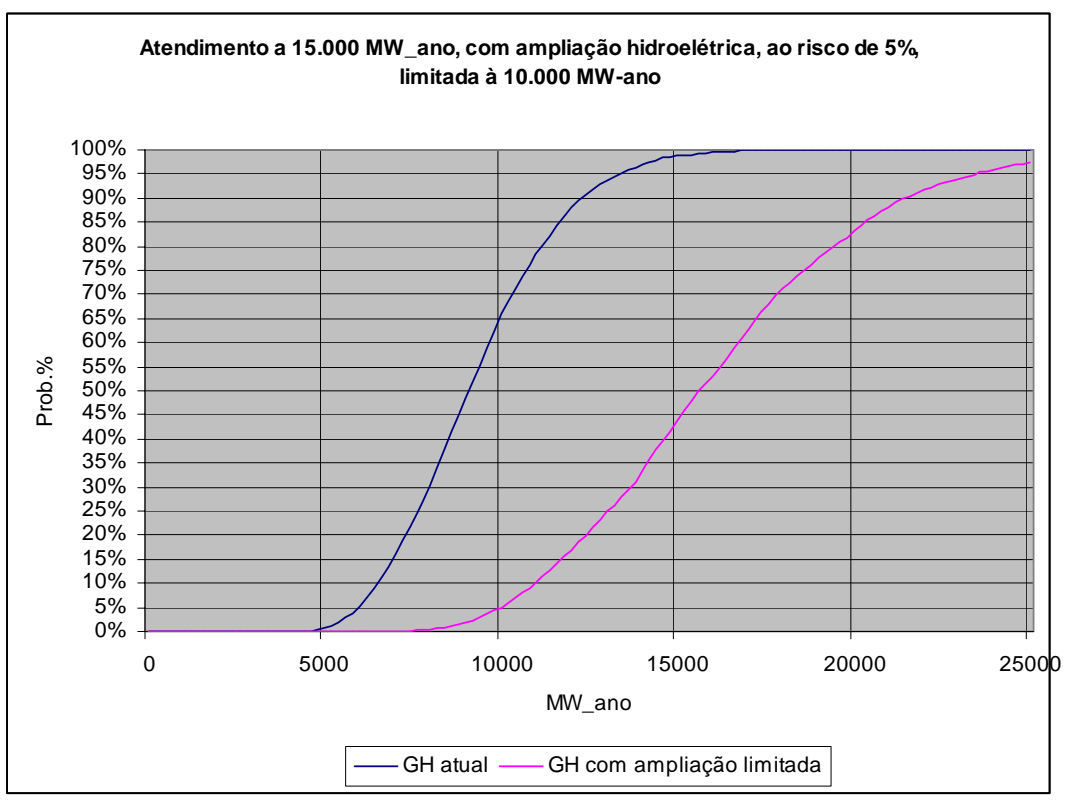

Figura 5 - Planejamento de expansão da geração com ampliação mista (44\% hidro e 54\% térmica). 
Nessa opção de expansão mista, instalando-se 4.000 MW_ano adicionais de hidrelétricas e 5.000 MW_ano de termelétricas, ou seja, uma composição 44\% hidro e 56\% térmica, a mediana da geração hidrelétrica $G H$ seria, pelo que se observa no gráfico, até um pouco maior que os $15.000 \mathrm{MW}$ _ano (se para isso houvesse capacidade instalada suficiente de $G H$ ), o que significaria que o valor esperado da geração térmica complementar poderia ser até zero. Nessa alternativa de expansão, o custo esperado do plano de expansão seria o custo da expansão hidrelétrica somado apenas ao de investimento das termelétricas, já que o custo operacional esperado do parque térmico seria nulo.

Caso o custo fixo marginal de termelétrica seja menor que o correspondente de hidrelétrica, o que é o esperado, exceto para hidrelétricas muito competitivas, porquanto o mais oneroso nas térmicas é o custo variável de operação, haveria ainda espaço, com o objetivo de minimizar o custo total esperado do plano de expansão, para se aumentar ainda mais a participação térmica na expansão, além dos 5.000 MW_ano, no atendimento complementar aos 15.000 MW_ano.

Por exemplo, caso, em nova iteração, a ampliação hidrelétrica reduzida para apenas 2.000 MW_ano, de forma que o sistema hidrelétrico garantisse 8.000 MW_ano, no nível de risco de $5 \%$, o parque térmico haveria de garantir os outros $7.000 \mathrm{MW}$ ano, para compor os 15.000 MW_ano projetados, ou seja, uma composição de $22 \%$ hidrelétrica e $78 \%$ termelétrica na expansão. O que resulta, desta alternativa, em termos de FDA de $G H$, é apresentado na Figura 6.

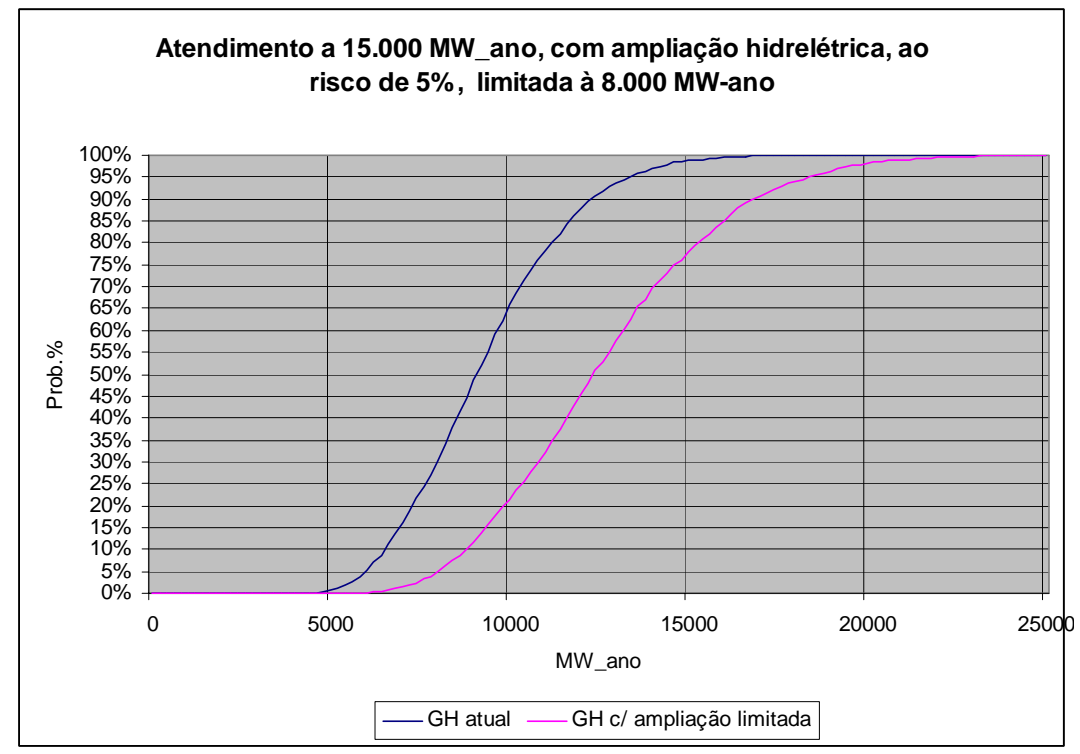

Figura 6 - Planejamento de expansão da geração com ampliação mista (22\% hidro e 78\% térmica).

Verifica-se, pela figura anterior, que a mediana da FDA de $G H$ com a expansão hidrelétrica limitada a 8.000 MW_ano e no nível de risco de 5\%, seria da ordem de 12.300 MW_ano.

Logo, a geração térmica esperada para complementar os $15.000 \mathrm{MW}$ _ano seria de 2.700 MW_ano, e não os 7.000 MW_ano garantidos que substituiu a expansão hidrelétrica. 
Ou seja, o fator de uso esperado do parque térmico, dimensionado para 7.000 MW_ano, seria de apenas $38,5 \%$, isto é, teria uma redução de $61,5 \%$.

O custo esperado incremental incorrido, ao se elevar a dimensão do parque térmico de 5.000 MW_ano para 8.000 MW_ano, haveria de ser comparado com o ganho decorrente da redução de se incrementar o parque hidrelétrico, não em 4.000 MW_ano, mas em apenas 2.000 MW_ano.

Conclui-se, portanto, que haverá uma determinada composição ótima hidrotérmica para atendimento à carga projetada a atender, no futuro, que resulte em um valor mínimo do custo total esperado do plano de expansão e o ponto onde ocorre esse mínimo não é, necessariamente, com expansão 100\% hidrelétrica, podendo este ponto ser obtido variando-se a expansão hidrelétrica entre a condição de expansão 100\% hidrelétrica, limitada ao potencial hidrelétrico disponível, e a condição expansão 100\% térmica, ou seja, 0\% hidrelétrica.

Feitas tais considerações, por processo da explicação gráfica simples, que aqui criamos, neste trabalho, para melhor entendimento do desafio da hidroeletricidade, sem se precisar recorrer ao uso de modelos de simulação sofisticados, nem sempre bem entendidos pelos não iniciados no assunto, cabe voltar, para concluir, o antes exposto sobre a abordagem desenvolvida por GUEDES FILHO et al. (2003), no estudo da Tendências Consultoria Ltda, para a Abraget.

\subsection{Um procedimento para determinação da composição ótima de um sistema hidrotérmico em estudos de longo prazo.}

O que Guedes Filho et al. (2003) fizeram, através de uma sofisticada e inovadora modelagem matemática, e focalizando o Sistema Interligado Brasileiro, este representado por uma usinareservatório equivalente a um parque térmico complementar, conforme já descrevemos, foi usar, de certa forma, a abordagem clássica de otimização de planejamento da expansão de sistemas de geração de energia elétrica, similar àquelas contidas em Knight (1972), em Verdi \& Avi-Itzhak (1981) e em Trinkenreich et al. (1980).

A diferença, sobre essa última, foi não usar conceito de regiões elétricas (subsistemas), mas sim um único sistema hidrelétrico equivalente Brasil, e por usar a função de distribuição acumulada de probabilidade da energia hidrelétrica, para com ela calcular a função de probabilidade acumulada do requisito de geração total do parque termelétrico e, assim, não adotar apenas as energias hidrelétricas de período crítico e/ou de hidrologia média, como são tratadas as hidrelétricas pelo modelo DESELP.

A modelagem adotada por Guedes Filho et al. (2003), repetimos, específica para um sistema equivalente formado por uma única usina-reservatório e um parque térmico complementar, pode ser entendida, sem se perder na sofisticação matemática, de uma forma relativamente fácil ao idealizarmos o seguinte procedimento a se aplicar em estudos de longo prazo, que apresentamos a seguir:

a) Passo 1: Considere-se a FDA da geração hidrelétrica $(G H=E N A+E A R)$ do sistema hidrelétrico a estudar, seja o Interligado Brasileiro ou o subsistema Nordeste, considerando a $E A R$ como uma constante ou mesmo como uma variável aleatória, com respectiva FDA do estado estacionário futuro de $E A R$.

Seja, por exemplo, a FDA de $G H$ correspondente à hipótese com geração hidrelétrica limitada a 8.000 MW_ano, ao risco de 5\%, indicada na Figura 7, a seguir reproduzida. 


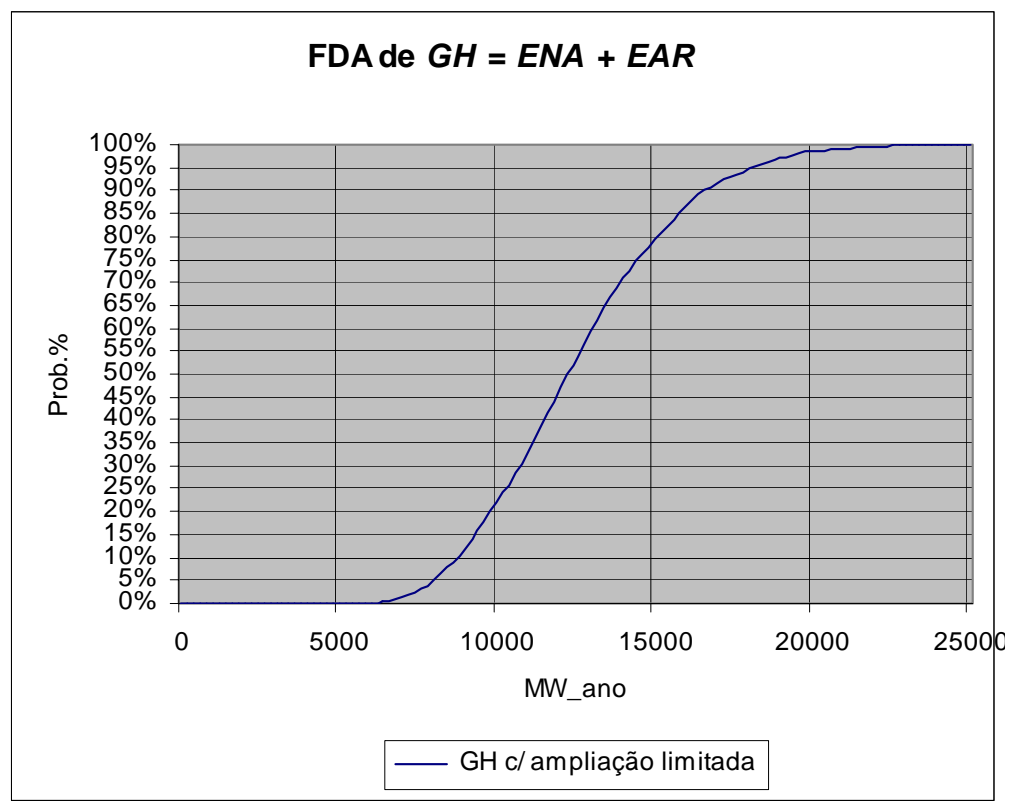

Figura 7 - FDA de GH.

b) Passo 2: Imagine-se o gráfico da FDA de GH girado em $90^{\circ}$, no sentido horário, como indicado a seguir:

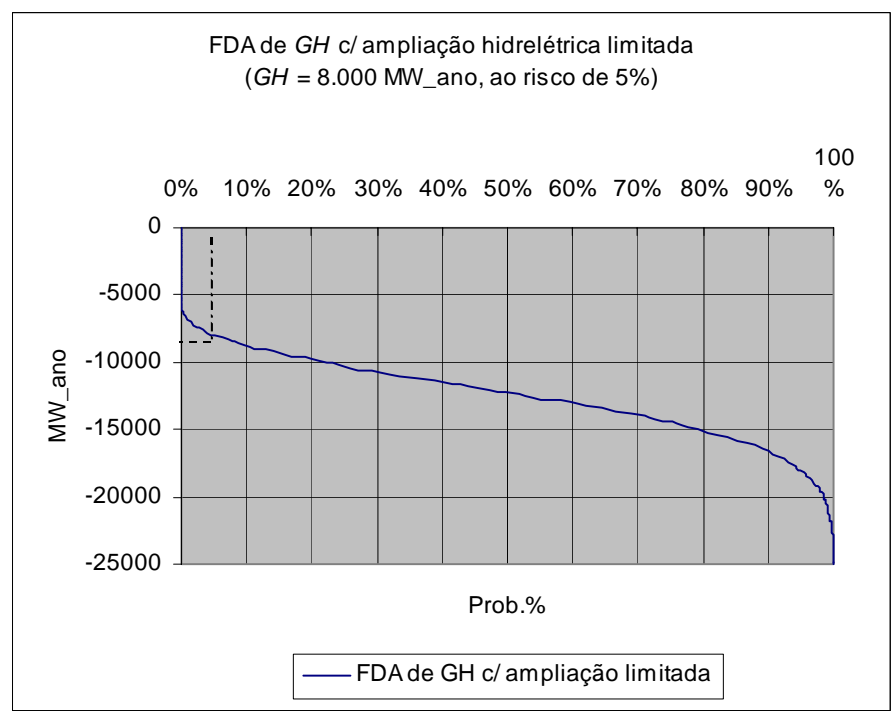

Figura 8 - FDA de GH, com um giro de $90^{\circ}$, no sentido horário. 
Desconsidere-se o sinal negativo do eixo das ordenadas, que é tão somente uma limitação do artifício usado para apresentar a FDA de GH girado em $90^{\circ}$, no sentido horário.

O que se obtém, como se observa, é uma "nova visão" da curva da FDA de GH, agora muito parecida com uma curva de duração de carga (load-duration-curve - LDC), na qual o eixo dos $\mathrm{x}$ 's, em \%, expressa a probabilidade $\operatorname{Pr}(\mathrm{x} \leq \mathrm{GH})$. Essa probabilidade é a expectativa do percentual do tempo de duração de um subperíodo (ano - caso se deseje trabalhar com subperíodos com duração maior que um ano, deve-se ajustar a FDA da $E N A$ e recalcular a $E A R$ ), do período (horizonte) de planejamento, que se poderá contar com a correspondente quantidade de energia GH, expressa em MW_ano. Vista sobre este ângulo, a FDA de GH indica qual a probabilidade de ocorrência de valores de GH iguais, ou menores, que um qualquer escolhido. Por exemplo, na hipótese de ampliação hidrelétrica limitada a 8.000 MW_ano (ao risco de 5\%), há uma probabilidade da ordem de $20 \%$ de ocorrência de GH $\leq 10.000$ MW_ano, o que significa que tal nível de geração hidrelétrica tem uma garantia da ordem de $80 \%$. Indica, também, que há uma probabilidade de apenas 20\% da carga de 15.000 MW_ano ser atendida exclusivamente por GH, desde que haja capacidade instalada para tanto.

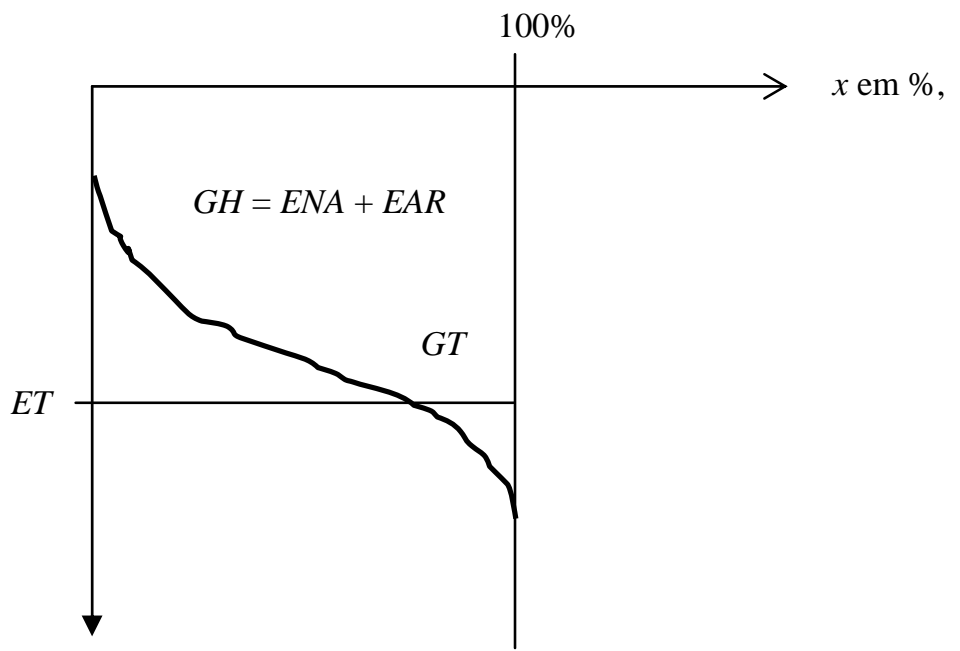

Figura 9 - Rotação de $90^{\circ}$ no sentido horário na FDA’s de GH em MW médio_ano.

c) Passo 3: Obtenha-se a FDA de GT, o que pode ser feito fazendo-se:

$$
G T=E T-G H,
$$

onde ET é a energia total projetada para o ano (ou subperíodo, do tipo quinquênio), no qual se deseja estudar a composição ótima do sistema hidrotérmico, em foco.

Para atender a uma carga ET =15.000 MW_ano, sob a hipótese de GH = 8.000 MW_ano, ao risco de $5 \%$, obtém-se a seguinte FDA de $G T$, indicada também em posição similar à FDA de $G H$, que foi apresentada na Figura 9. 


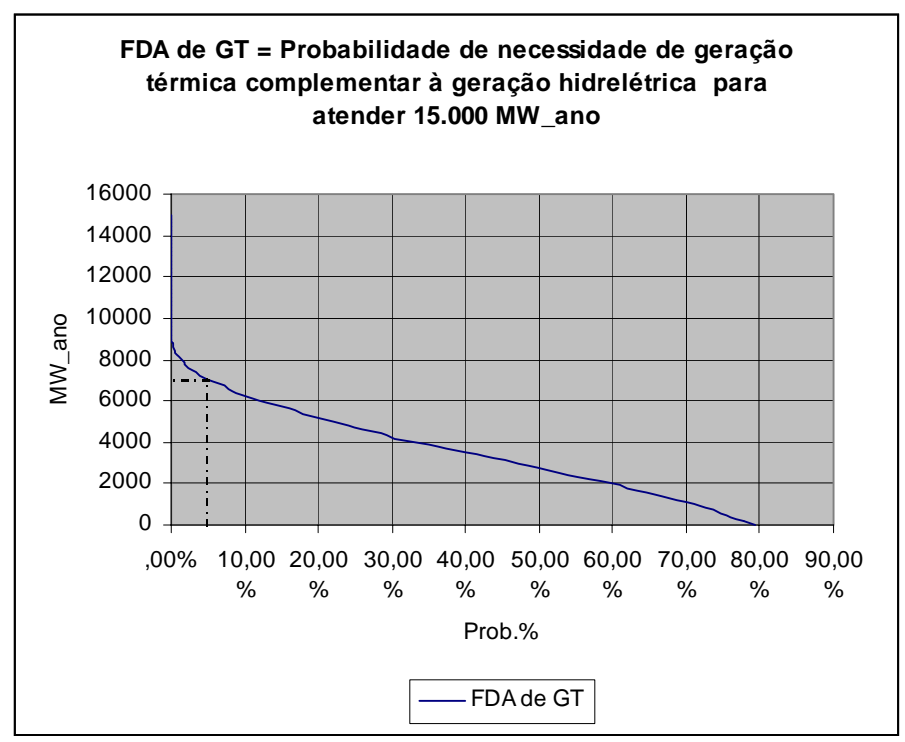

Figura 10 - FDA de GT, complementar para ET = 15.000 MW_ano.

A FDA de GT acima, válida para ET = 15.000 MW_ano, indica que pode haver uma necessidade de, no mínimo, 7.000 MW_ano de geração térmica complementar, com uma probabilidade de ocorrência de 5\%. Essa probabilidade deriva da probabilidade de ocorrência de GH menor ou igual a 8.000 MW_ano, pois a característica probabilística de GT é função do quanto se terá de GH. Para um nível da mediana de GH, a GT esperada é, apenas, da ordem de 2.700 MW_ano, antes já comentada.

A FDA de GT tem, portanto, um formato de uma LDC, conforme figura a seguir, representando a indicação da probabilidade dos requisitos de geração (GT) que poderão ser solicitados do parque térmico para complementar uma determinada geração hidrelétrica (GH), no atendimento de uma carga total ET.

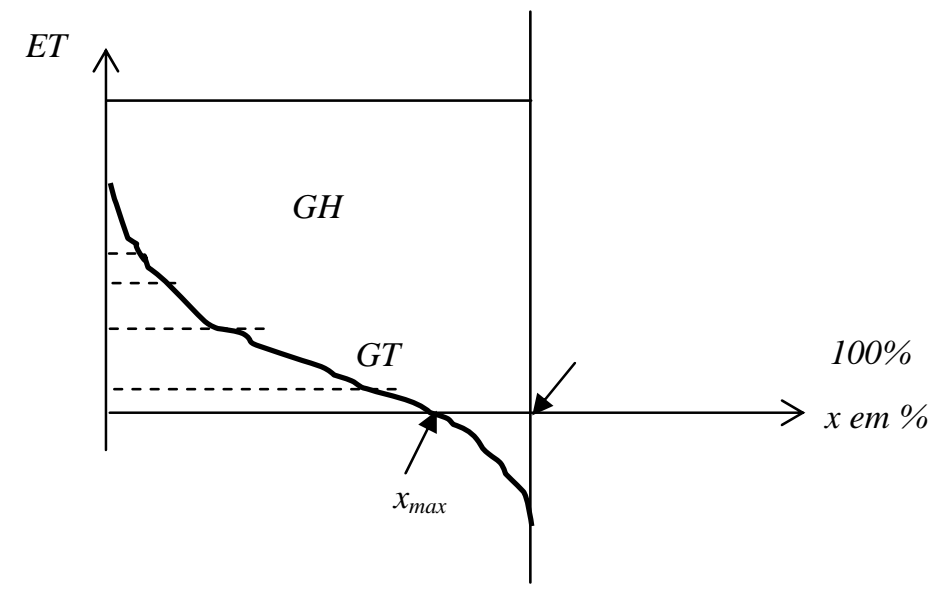

Figura 11 - Obtenção da FDA’s de GT. 
d) Passo 4: Use-se a FDA de $G T$, no intervalo $\left[0, x_{\max }\right]$, como uma imagem da "LDC equivalente" do requisito exigido do parque térmico, associada a " $0 \%$ de expansão hidrelétrica" e ao valor ET projetado, a qual deve "patamarizada" (quanto maior o número de patamares, mais bem representativa fica a "LDC" com expressão da LDC da GT), em vários intervalos. Assim pode-se definir a composição ótima de plantas geradoras do tipo $i$ (usinas térmicas a instalar), através de Programação Linear (PL), adotando-se diferentes tipos de térmicas (uma das térmicas poderia ser a "fictícia" representando a admissibilidade de déficit), com os respectivos custos de investimento (\$/kW) e de operação (\$/MWh), variando-se em combustível e/ou em nível de flexibilidade operativa, de forma que se minimize o custo total esperado de expansão do parque térmico. Essa seria a solução ótima com "expansão 100\% térmica”, ou seja, com " $0 \%$ de expansão hidrelétrica", tendo como base a configuração hidrelétrica inicial adotada de $8.000 \mathrm{MW}$-ano ao risco de $5 \%$.

e) Passo 5: Caso a "expansão 100\% térmica" apresente um custo total esperado maior do que o custo da "expansão 100\% hidrelétrica”, que é o que deve geralmente acontecer, exceto que se esteja tentando utilizar hidrelétricas de elevado custo total de produção, portanto não competitivas, incremente-se, progressivamente, por etapas discretas, o parque hidrelétrico, para uma participação na expansão, de $0 \%$ e indo até $100 \%$, ou até atingir o teto do potencial hidroelétrico visto como competitivo. Isto provoca deslocamento e/ou dilatação da FDA de $G H$ e, portanto, reduz a necessidade de GT, baixando a curva correspondente na FDA de GT. Para cada etapa, encontre-se, por meio de PL, a composição ótima do parque térmico, igualmente ao item (d) anterior.

f) Passo 6: A composição ótima do parque gerador hidrotérmico, no horizonte futuro em avaliação, sob o enfoque mono-objetivo, seria aquela que, por convergência, resultar no mínimo custo total da expansão, ou seja, considerando tanto os custos de investimento e de operação, tanto da expansão hidrelétrica como da expansão térmica, além de montantes e custos representativos de déficits que sejam admitidos, observando-se que os déficits são representados por uma "térmica fictícia" sem custo fixo e com custo variável igual ao custo social do déficit definido ou decretado.

Cabe observar que o ponto de mínimo do custo total da expansão hidrotérmica situar-se-á em uma participação percentual do parque térmico, na expansão, superior a $0 \%$ e inferior a $100 \%$, havendo, portanto, um ponto intermediário a se determinar, exceto na situação de “expansão 100\% hidrelétrica” que tenha custo marginal (R $\$ / M W h)$ menor do que a parcela do custo fixo (expresso também em R $\$ / M W h$ ) das térmicas de menor custo de investimento, que são as de ciclo aberto com turbinas a gás.

Muito embora Guedes Filho et al. (2003) tenham descartado patamares de custo do déficit crescentes com a profundidade do déficit, isto poderia ser facilmente implementado, no modelo e no procedimento, ao se definir diversas térmicas fictícias com limites de capacidades, fixados e iguais às larguras dos patamares, e com custos variáveis, em degraus crescentes, igualados aos custos de déficit dos patamares, deixando-se a térmica fictícia de custo variável mais alto sem o limite de capacidade.

Caso se deseje limitar a profundidade máxima admissível para o déficit, por opção do decisor em coerência com o que a sociedade poderia aceitar, adotando-se, assim, uma certa elasticidade ao mercado, bastaria que a térmica fictícia, de maior custo variável, tivesse também um limite de capacidade. Pelo modelo, uma vez ela fique cheia, déficit’s superiores ao máximo admissível seriam cobertos com geração térmica flexível a custo de maior investimento. 
Destarte, seja pela modelagem do DESELP, exposta em Trinkenreich et al. (1980), como na forma alternativa indicada no procedimento exposto neste item, inspirado na abordagem de Guedes Filho et al. (2003), fica demonstrado que se pode desenvolver uma metodologia de otimização para definir a trajetória de evolução da composição do "mix energético" de um parque hidrotérmico em sistemas preponderantemente hidrelétricos, como é o do Brasil suportado no procedimento exposto e em Programação Linear (PL), que possibilite maior garantia energética e menor custo de expansão que as metodologias até então adotadas no Brasil.

Tal resultado é importante, finalizando o estudo e a reflexão objeto deste trabalho, pois, se acoplada à metodologia desenvolvida em Clímaco et al. (2003), além de abrir espaço de viabilidade técnica para um projeto de desenvolvimento de aplicação da PLMO no planejamento de expansão de longo prazo da geração de energia elétrica do Sistema Interligado Brasileiro.

Observa-se que o ponto de mínimo custo total da expansão hidrotérmica, em uma dada janela do horizonte de planejamento de longo prazo, seria definido, não em cima de uma linha, como feito em Guedes Filho et al. (2003), mas em uma superfície em dimensão $\mathrm{R}^{p+1}$, onde $p$ é o número de objetivos adotados, melhor instrumentalizando o planejamento para interagir com a realidade multiobjetivo da sociedade.

\section{Conclusões}

O trabalho demonstrou um caminho para aplicabilidade da PLMO no planejamento do "mix energético" da expansão de longo prazo da geração no sistema brasileiro, associando os desenvolvimentos feitos no passado por Trinkenreich et al. (1980) e mais recentemente por Guedes Filho et al. (2003).

A consideração simultânea de diferentes objetivos e não apenas o de mínimo custo da expansão permitirá uma melhor interação entre os planejadores e os formuladores de políticas de expansão, facilitando o processo sociopolítico intrínseco em uma área de alto interesse estratégico, como é a de oferta futura de energia elétrica para uma Nação.

O principal objetivo deste trabalho é provocar a introdução da PLMO no processo de planejamento do setor elétrico, o qual hoje vem dando passos largos pelo Ministério de Minas e Energia (MME) com o apoio da Empresa de Pesquisa Energética (EPE), requerendo contudo um suporte metodológico mais apropriado para consideração dos naturais múltiplos objetivos a serem considerados nesse campo de decisão.

\section{Agradecimentos}

Este trabalho teve suporte parcial do CNPq e da CHESF.

\section{Referências Bibliográficas}

(1) Albuquerque, L.L. (2004). Planejamento do "Mix Energético" de Geração de Energia Elétrica no Brasil. Dissertação de Mestrado, Departamento de Engenharia de Produção, UFPE.

(2) Antunes, C.H.; Alves, M.J.; Silva, A.L. \& Clímaco, J. (1989). Algumas reflexões sobre uma base de métodos de programação linear multicritério. Investigação Operacional, 9(2), 19-35. 
(3) Antunes, C.H.; Alves, M.J.; Silva, A.L. \& Clímaco, J.N. (1992). An integrated MOLP method base package - a guided tour of TOMMIX. Computers and Operations Research, 19(7), 609-625.

(4) Antunes, C.H.; Martins, A.G. \& Brito, I.S. (2001). A multiple objective mixed integer linear programming model for power generation expansion planning. INESC-Coimbra, Portugal.

(5) Campello de Souza, F.M. (2002). Decisões Racionais para Situações de Incerteza. Editora Universitária UFPE.

(6) Clímaco, J.N.; Antunes, C.H. \& Alves, M.J.G. (2003). Programação Linear Multiobjetivo. Imprensa da Universidade de Coimbra, Portugal.

(7) Clímaco, J.N.; Antunes, C.H. \& Alves, M.J.G. (1997). From TRIMAP TO SOMMIX Building Effective Interactive MOLP Computational Tools. In: Multiple Criteria Decision [edited by G. Fendel and T. Gal], LNMES, 448, Springer-Verlag, 285-296.

(8) Evans, J. \& Steuer, R. (1973). A revised simplex method for multiple objective programs. Mathematical Programming, 5(1), 54-72.

(9) Gomes, L.F.A.M.; Gomes, C.F.S. \& Almeida, A.T. (2002). Tomada de Decisão Gerencial. Enfoque Multicritério. Editora Atlas, São Paulo, Brasil.

(10) Guedes Filho, E.M.; Amadeo, E.; Hochsteller, R.L. \& Rojas, A. (2003). O risco de déficit e o papel da geração térmica no Brasil: qual composição otimizada do parque gerador?. Tendências Consultoria Integrada, São Paulo, Brasil.

(11) Fortunato, L.A.M.; Araripe Neto, T.A.; Albuquerque, J.C.R. \& Pereira, M.V.F. (1990). Introdução ao Planejamento da Expansão e da Operação de Sistemas de Produção de Energia Elétrica. Eletrobrás, Editora Universitária, Universidade Federal Fluminense, Niterói, Rio de Janeiro, Brasil.

(12) Hadley, G. (1973) Linear Programming. Addison-Wesley Publishing Company, Reading, Massachusetts, USA.

(13) Hunt, S. \& Shuttleworth, G. (1996). Competition and Choice in Electricity. John Wiley \& Sons, Great Britain.

(14) Leite, A.D. (1997). A Energia no Brasil. Nova Fronteira, Rio de Janeiro.

(15) Kagiannas, A.G.; Askounis, D.T. \& Psarras, J. (2004). Power generation planning: a survey from monopoly to competition. Electrical Power \& Energy Systems, 26, 413-421.

(16) Keeney, R.L. \& Raiffa, H. (1976). Decision with Multiple Objectives: Preferences and Value Tradeoffs. John Wiley \& Sons.

(17) Knight, U.G. (1972). Power Systems Engineering and Mathematics. Pergamon Press, Printed in Germany.

(18) Memória de Eletricidade. (2002). O planejamento da expansão do setor de energia elétrica: a atuação da Eletrobrás e do Grupo de Planejamento dos Sistemas Elétricos (GCPS).

(19) Pereira, M.V.F. \& Pinto, L.M.G. (1985). Stochastic Optimization of a Multireservoir Hydroelectric System: A Decomposition Approach. Water Resources Research, 21(6), 779-792. 
(20) Pereira, M.V.F. (1989). Optimal stochastic operations scheduling of large hydroelectric systems. Electric Power \& Energy Systems, 11(3), July 1989.

(21) Stevenson Jr, W.D. \& Grainer, J.J. (1994). Power System Analysis. McGraw Hill, Inc. International Editions.

(22) Steuer, R. (1986). Multiple Criteria Optimization: Theory, Computation and Application. Wiley.

(23) Trinkenreich, J.; Wanderley, V.M.; Albuquerque, J.C. \& Pinheiro, S.F. (1980). Modelo de Análise da Expansão a Longo Prazo do Sistema Interligado Brasileiro. Subcomitê de Planejamento de Sistemas Elétricos, Comitê Brasil, CIER.

(24) Vanderbei, R.J. (1996). Linear Programming: Foundations and Extensions. Kluwer Academic Publishers.

(25) Vardi, J. \& Avi-Itzhak. (1981). Electric Energy Generation. Economics, Reliability and Rates. The MIT Press, Cambridge, Massachusetts and London, England.

(26) Zenely, M. (1974). Linear Multiobjective Programming. Springer-Verlag, New York.

(27) Zenely, M. (1982). Multiple Criteria Decision Making. McGraw-Hill, New York. 